\title{
Oxygen enriched combustion
}

\author{
Shanshan Xie ${ }^{1, a}$ Hui Li ${ }^{1, b}$ \\ College of Metallurgy and Energy, North China University Of Science And \\ Technology, Tangshan Hebei 063009, China \\ a729055633@qq.com,,Ih@ncst.edu.cn
}

Key words: Oxygen enriched combustion, energy saving and environment

Abstract: Oxygen enriched combustion technology is an important branch of greenhouse gas emission reduction technology, which has been developed rapidly in recent years. This paper briefly introduces the method of oxygen enriched combustion and the energy saving characteristics and the influence of the environment on two aspects.

\section{Introduction}

So far, $80 \%$ of human consumption of energy has been obtained by burning, and the burning process of emissions is the main cause of environmental pollution. China's energy utilization is less than $40 \%$, so how to improve the utilization of resources and reduce the impact on the environment, the development of high efficiency and low emission technology is very active, oxygen enriched combustion, high temperature air combustion, catalytic combustion technology has shown its wide application prospect ${ }^{[1]}$.

Oxygen enriched air with high oxygen concentration $(21 \%)$ is used to burn, called oxygen enriched combustion. It is a highly efficient and energy-saving combustion technology, in the glass industry, metallurgy industry and the field of thermal energy engineering are applied. Oxygen enriched combustion can significantly improve the combustion efficiency and flame temperature.

\section{Theoretical basis of oxygen enriched combustion technology}

The combustion is caused by the high energy collision between the fuel and the oxygen molecule, so the supply of oxygen determines whether the combustion process is complete. Oxygen enriched air (OEC) with oxygen concentration of oxygen enriched air, which is used in air (with oxygen $21 \%$ ), is called oxygen enriched combustion (oxygen enriched combustion). It is a highly efficient and energy-saving combustion technology, in the glass industry, metallurgy industry and the field of thermal energy engineering are applied. Oxygen enriched combustion has the following advantages compared with ordinary air combustion.

\section{The high flame temperature and emissivity}

Combustion process is the process of oxygen in the air to participate in the oxidation of fuel and emit light and heat. Heat transfer is usually transmitted through three ways of radiation, conduction and convection. Radiant heat transfer is one of the main ways of boiler heat transfer. According to the characteristics of gas emission, only three atoms and multi atomic gases have the ability of radiation. So in conventional combustion air, no radiation ability of nitrogen proportion is very high, so the blackness of the smoke is very low, affecting the flue gas of boiler convection and radiation heat of heat transfer surface. Reduce the oxygen enriched combustion technology for nitrogen gas, amount of air and flue gas volume were significantly reduced, so of flame temperature and emissivity with combustion air oxygen ratio increased significantly improve and improve flame 
radiation intensity and radiation heat transfer enhancement.

\section{Accelerate the burning rate and promote the burning completely.}

The burning rate of fuel in air and in pure oxygen difference .Large, such as the burning rate of hydrogen in pure oxygen in the air is 4.2 Times, natural gas is about 10.7 times. The use of oxygen enriched combustion air .After, not only to make the flame shorter, improve the burning intensity, speed up the burning speed.

Good heat conduction, and due to the increase in temperature, will be beneficial to Combustion reaction.

\section{Application of oxygen enriched combustion in metallurgical industry}

The heat generated by the fuel combustion in the furnace is a large part of the flue gas away from the furnace (about $40 \%$, excluding the waste heat recovery). The average temperature of the furnace flue gas is up to $500 \sim 1400$, which takes about the heat load of the furnace $20 \% \sim 60 \%$.Oxygen enriched combustion of heating furnace is the pure oxygen combustion supporting air pipes pass into, make the mixture evenly, in order to improve the concentration of oxygen and the uniform contact with the fuel, combustion stability ${ }^{[2]}$.

\section{Oxygen enriched combustion energy}

The flame temperature is greatly improved, and the adiabatic flame temperature of $30 \%$ oxygen enriched air is $2500 \mathrm{~K}$, The flame temperature close to $3000 \mathrm{~K}$ with the oxygen concentration greater than $80 \%$ when the oxygen concentration is greater than, the laminar burning velocity is increased to $3 \mathrm{~m} / \mathrm{s}$, while the average air flow rate is only $0.45 \mathrm{~m} / \mathrm{s}$. Through the oxygen enriched combustion can improve the combustion intensity and accelerate the combustion rate and get better heat conduction, while the temperature increase is favorable to the combustion reaction.

$1 \mathrm{~kg}$ solid or liquid fuel in the case of the $\mathrm{a}=1$ is completely burned, and the generated amount of flue gas is a theoretical gas quantity, with a formula

$$
\mathrm{V}^{\mathrm{o}}=\mathrm{VcO}_{2}+\mathrm{V}_{\mathrm{H} 2 \mathrm{O}}+\mathrm{V}_{\mathrm{N} 2}
$$

Due to the concentration of inert components of nitrogen is greatly reduced, and the consumption of the unnecessary energy consumption is greatly reduced ${ }^{[3]}$, the oxygen enriched air of $40 \%$ to $30 \%$ can be reduced by $30 \%$ to $20 \%$ of the fuel consumption.

Flue gas volume is reduced greatly, quarter only ordinary air combustion of pure oxygen combustion flue gas volume, increase the concentration of $\mathrm{CO}_{2}$ in flue gas, is conducive to recycling comprehensive utilization or storage, cleaner production ${ }^{[4]}$; flue gas in high radiation rate of $\mathrm{CO}_{2}$ and water vapor concentration increases, can increase the density of promote the radiative heat transfer in the furnace.

The size of the device is reduced, and the cost of equipment investment and maintenance costs of the system are reduced ${ }^{[5]}$.

\section{Effect of oxygen enriched combustion on Environment}

The generation of NOx is about 4 times higher than that of air in $30 \% \sim 40 \%$. Pure oxygen combustion is theoretically zero NOx emissions ${ }^{[6]}$, but the actual combustion equipment could not do completely closed, oxygen concentration in $99 \%$ of NOx emissions is also common air combustion of nearly six times. On this basis, they change the speed gradient in the process of burning, and the NOx thermal model decreases sharply with the increase of the velocity gradient, so the total NOx also decreases. This shows that the generation of NOx can be effectively reduced 
with the increase of the velocity gradient ${ }^{[7]}$. The main reason is that the residence time of the reactants in the high temperature region is reduced, which reduces the generation of thermal NOx.

\section{Conclusions}

With the increase of oxygen, the combustion efficiency and combustion temperature of the fuel are improved. But the unreasonable proportion of oxygen, will increase the amount of NOx generated, resulting in environmental pollution. And too high temperature will reduce the furnace life, increase oxygen and equipment costs.

Oxygen enriched combustion flame temperature higher.Heat transfer efficiency and energy utilization and can get better ignition characteristics.Improve the flame stability and the increase of the flame speed. Improved flame characteristics and flame shape control \& exhaust volume reduction.Can increase production flexibility Oxygen enriched combustion can be applied in metal heating and melting. The melting and mineral roasting high temperature heating industry in those who pass!Heat efficiency is low impact productivity increase heat transfer but not affect product .Quality and limited by the smoke exhaust system can not improve the productivity and so on. The application potential of oxygen enriched combustion in the field of heating will become increasingly large.

\section{Acknowledgements}

This work was financially supported by the National Natural Science Foundation of China (Grant No.51401075)

\section{Reference}

[1]Hongyu Li, Hua Wang. Performance comparison and analysis of low oxygen combustion and oxygen enriched combustion [J]. Industrial Heating.Vol.5 (2003), 32,p.9-12. In Chinese

[2]Fengqiong $\mathrm{Xu}$. Application and development of oxygen enrichment in metallurgy [J].Yunnan Metallurgy.Vol.2 (1999),28,p.31-35. In Chinese

[3]Qiaofang Cai. Heating furnace[M].Beijing: Metallurgical Industry Press, (1996),P.208-219. In Chinese

[4]Tingji Wang.NOX emissions and oxygen enriched combustion of glass furnaces [J]. China Building Materials Science and Technology.Vol. 4 (1996) ,5,p.1- 4. In Chinese

[5]Daiqing Zhao, Yaoxun Feng et al. Effects of heat radiation on the structure and nitrogen oxide generation of oxygen enriched diffusion combustion flame $[\mathrm{J}]$. Thermal Power Engineering.Vol.3(2005),20,p.275-279. In Chinese

[6]Rixin Liu. Testing of heating temperature of continuous casting billet in large hot rolling reheating furnace [J]. Industrial Heating.Vol. 5 (2002),p.40-42. In Chinese

[7]Rixin Liu, Baolin Ning. Heating furnace operation dynamic mathematical model of [J]. Iron and steel. Vol.10 (1991), 26,p. 54-58. In Chinese 